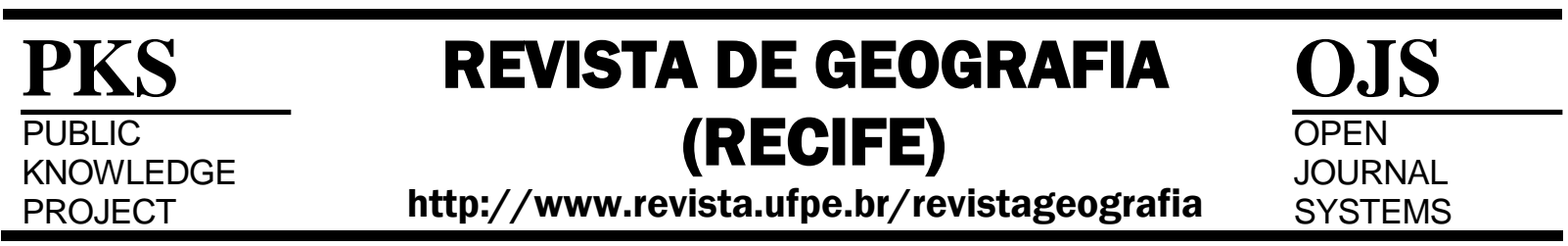

\section{O DESENHO DO NOVO RURAL: O CASO DO DISTRITO DE ARROIO GRANDE- SANTA MARIA/RS}

\author{
Tatiane Almeida Netto ${ }^{1}$; Janete Webler Cancelier ${ }^{2}$; Leonice Aparecida de Fátima Alves \\ Pereira Mourad ${ }^{3}$
}

\author{
${ }^{1}$ Doutora do Programa de Pós Graduação em Geografia da Universidade Federal de Santa Maria. Email: \\ tatianetto@gmail.com \\ ${ }^{2}$ Mestre em Geografia pela Universidade Federal de Santa Catarina.Email: janetewc@ gmail.com \\ ${ }^{3}$ Docente da Universidade Fedral de Santa Maria.Email: profleo@ig.com.br
}

Artigo recebido em 07/08/2016 e aceito em 13/08/2017

\begin{abstract}
RESUMO
Este trabalho tem por objetivo sistematizar cartograficamente como o espaço rural está se transformando com a inserção da multifuncionalidade no distrito de Arroio Grande, situado no município de Santa MariaRS. Para isso, buscou-se identificar e espacializar as atividades agrícolas e não agrícolas que caracterizam a multifuncionalidade do espaço rural do referido distrito. A metodologia foi baseada em tipologias da agricultura familiar identificadas através de entrevistas semiestruturadas e da análise das ocupações rurais não agrícolas evidenciadas por observação direta, além da revisão bibliográfica. A técnica de geoprocessamento possibilitou uma nova condição de armazenamento e manipulação de dados espaciais e socioeconômicos, onde, através do diagnóstico das tipologias das ocupações rurais agrícolas e não agrícolas identifica-se o desenho do novo rural.
\end{abstract}

Palavras-chave: Multifuncionalidade, Geoprocessamento, Pluriatividade, Novo Rural, Agricultura Familiar.

\section{THE NEW RURAL DESIGN: THE CASE OF ARROIO GRANDE DISTRICT - SANTA MARIA / RS}

\begin{abstract}
This work aims to cartographically systematize how the countryside is changing with the inclusion of multifunctionality in Arroio Grande district, in the municipality of Santa Maria-RS. For that purpose, we sought to identify and specialise agricultural and non-agricultural activities that characterize the multifunctionality of the rural space of the mentioned district. The methodology has been based on family farming typologies identified through semi-structured interviews and analysis of the non-farm rural occupations evidenced by direct observation, in addition to bibliopgraphic review. The geoprocessing technique has enabled a new storage condition and handling of spatial and socioeconomic data, which, through the diagnosis of the typology of agricultural and non-agricultural rural occupations identifies the design of the new rural.
\end{abstract}

Keywords: Multifunctionality, Geoprocessing, Pluriactivity, New Rural, Family Farming. 


\section{INTRODUÇÃO}

O espaço rural brasileiro está passando por significativas transformações com o surgimento de novas atividades econômicas não necessariamente agrícolas, o que tem despertado um amplo debate no meio científico em busca de uma (re)definição do conceito de rural brasileiro. Chamam-se essa modificação de novo rural, onde Schneider (1999) aponta que o meio rural deixou de ser um espaço que privilegia a agricultura e é, cada vez mais, um espaço de múltiplas atividades.

A atual transformação do paradigma produtivista é responsável pelas novas funções do rural, para além do agrícola, com a introdução de atividades de lazer e turismo, além do processo de urbanização da zona rural, com o aumento de serviços básicos como luz, educação e saúde (SANTOS et al., 2008).

O novo rural reconhece hoje a função social da agricultura, onde cabe aos agricultores não somente a produção de alimentos e a produção agropecuária, mas a inserção de atividades não agrícolas que criam e recriam novos produtos e serviços no espaço rural contribuindo para a diversificação das atividades, tais como conservação das características paisagísticas da região, preservação, conservação e proteção do capital cultural e ambiental do meio rural, suporte para a construção de identidades e memória, traduzindo as diferentes modalidades de interesses da atualidade como bem aponta Froehlich ( 2002).

Nas áreas peri-urbanas que circundam as grandes cidades, pode-se observar a nova função de lazer e moradia representada pelas chácaras e sítios, que fazem as atividades agrícolas destas propriedades se caracterizarem como uma atividade secundária, assinalando a presença da multifuncionalidade ${ }^{1}$ do espaço agrário, onde se integram novos valores e uma nova configuração de mercado de trabalho. Nestas áreas, Santos et. al. (2008) menciona que os moradores tendem a proteger as características rurais como a paisagem, o meio ambiente, de forma que se possam usufruir das mesmas, independentemente das demandas agrícolas.

O desenvolvimento rural e as novas ocupações de trabalho no rural são estabelecidos e proporcionados pelas construções sociais e relações sociais diversificadas em diferentes regiões. Para Wanderley (1997) as relações que se estabelecem entre o espaço rural e a cidade mais próxima são as que definem um espaço social diversificado.

Graziano da Silva (1997) destaca que se está criando um novo tipo de riqueza além dos produtos agrícolas, baseadas em bens e produtos não tangíveis, novas funções no espaço rural gerada através do novo ator social "agricultor pluriativo" com novos serviços e 
ocupações como lazer, turismo, conservação ambiental, moradia e demais atividades e serviços.

O espaço rural assume novos valores simbólicos, para Froehlich (2002) adquire uma nova legitimidade identitária, não mais se restringindo somente à 'alimentar' com a qual foi confundido por longo tempo. E essa "legitimidade é fundada na percepção do campo como símbolo de paisagem, beleza, liberdade, tranquilidade e saúde" (FROEHLICH, 2002, p. 208).

A emergência das novas funções do rural acaba por resultar na presença da pluriatividade, um fenômeno em que membros de famílias de agricultores, tradicionalmente ocupadas com atividades estritamente agrícolas, passam a desenvolver outras atividades como estratégia de reprodução social e complementação da renda. A pluriatividade, conforme descreve Schneider (1999), refere-se a situações sociais em que os alguns indivíduos que compõem uma família com domicílio rural passam a se dedicar ao exercício de um conjunto variado de atividades econômicas e produtivas, não necessariamente ligadas à agricultura ou ao cultivo da terra, e cada vez menos executadas dentro da unidade de produção. $\mathrm{O}$ crescimento de agricultores pluriativos decorre também do significativo incremento de renda decorrente de benefícios previdenciários e sociais, o que se deu prioritariamente a partir da Constituição Federal de 1988.

Neste contexto, a pluriatividade adquire duas conotações em sentidos distintos: de um lado, é resultado da fragilidade das atividades primárias, em um contexto de crescente urbanização e industrialização. De outro lado, está vinculada a uma ressignificação do rural, espaço não mais restrito ao agrícola, como evidencia a demanda por turismo e lazer, sendo importante salientar também uma nova concepção do agrícola, pela potencialidade de produtos de qualidade e de origem passíveis de serem conhecidos pelo consumidor. Dessa forma, a inserção da pluriatividade e a geração de renda com as atividades para-agrícolas na contemporaneidade vêm produzindo um espaço rural multifuncional.

As atividades para-agrícolas segundo Gavioli (2010, p.43) estariam associadas à "ocupação em tempo integral no estabelecimento familiar ou em atividades paralelas à agricultura como as agroindústrias que processam e agregam valor aos produtos in natura". Já na pluriatividade tem-se o arranjo entre as atividades agrícolas e as atividades não agrícolas como a ocupação em fábricas, comércio, restaurantes, etc. Dessa forma, as "atividades paraagrícolas fortalecem a agricultura familiar e expressam a multifuncionalidade da agricultura". (LACERDA; MORUZZI MARQUES, 2008, p. 13). 
Diante do exposto, procuramos entender que no Distrito de Arroio Grande, Santa Maria-RS, o rural não possui uma essência a histórica, mas uma essência que muda no tempo, como bem exemplifica Wanderley (2000). Concordamos com a autora para o fato de estar ocorrendo o estabelecimento de um novo rural, com novas características, novas formas de se relacionar com o meio, mais aberto à sociedade e com novas configurações de organização interna; um espaço no qual se territorializam e se manifestam, além das atividades agrícolas, atividades ligadas aos mais diversos segmentos, entre elas: turismo, lazer, descanso, agroindustrialização, etc.

A presente pesquisa foi realizada no Distrito de Arroio Grande, município de Santa Maria - RS. Através do qual foram extraídos os dados para análise da multifuncionalidade do espaço rural em questão, diagnosticados através de entrevistas semiestruturadas e pesquisa empírica, abrangendo a análise do sistema de produção das unidades familiares e análise das novas ruralidades.

O meio rural na região central ${ }^{2}$ do estado do Rio Grande do Sul abarca uma diversidade de oferta de serviços, atividades, lugares e estabelecimentos do espaço rural, onde segundo Froehlich (2002) o aumento em estabelecimentos de lazer e turismo é uma resposta à demanda de consumo da natureza, do rural como natureza, associado a uma noção positiva sobre os planos simbólico e prático, do contato da sociedade com o ambiente (FROEHLICH, 2002; FROEHLICH et al., 2008).

No âmbito da metodologia evidencia-se a hipótese de que as técnicas do geoprocessamento possibilitarão uma nova condição de armazenamento e manipulação de dados espaciais e socioeconômicos, considerados de grande importância para gestão, favorecendo o acompanhamento das reais necessidades de cada localidade.

Sob o ponto de vista de Graziano da Silva (1997) o surgimento das atividades rurais não agrícolas é uma tendência tanto em países desenvolvidos como subdesenvolvidos remetendo a ideia de um continuum espacial, seja do ponto de vista de sua dimensão geográfica e territorial como na dimensão econômica e social, ao afirmar isso não estamos reiterando a tese muito consolidada nos estudos geográficos, acerca da inexorabilidade do urbano, visto que o rural, e prioritariamente o rural brasileiro e Latino Americano é marcado por um conjunto expressivo de singularidades.

$\mathrm{Na}$ contemporaneidade, as unidades agrícolas familiares tornam-se pluriativas, conforme descreve Schneider (2003), no momento em que o espaço rural converte-se em um espaço mercantilizado de bens e serviços, devido à competição da nova configuração de 
mercado trabalho. Neste contexto percebe-se uma mudança nos processos produtivos, nas organizações sociais, nos hábitos de produção e consumo e noções do que é rural e urbano.

Dessa forma, este artigo procura compreender como estas relações se manifestam no distrito de Arroio Grande, assim como identificar e espacializar as informações georreferenciadas de dados que caracterizam a multifuncionalidade e a pluriatividade do espaço rural do Distrito de Arroio Grande, Santa Maria-RS.

\section{A ÁREA DE ESTUDO}

O município de Santa Maria - RS está localizado na região central do Estado do Rio Grande do Sul. Possuiu uma população de 262.368 mil habitantes, sendo que mais de 95\% desta população vivem na área urbana (IBGE, 2014). Sua configuração territorial está associada ao processo de ocupação e formação socioeconômica da região central do Rio Grande do Sul. Atualmente, em sua composição administrativa, o município é composto por dez distritos, conforme Figura 1, entre eles o distrito de Arroio Grande.

Figura 1: Localização do município de Santa Maria-RS e de seus distritos

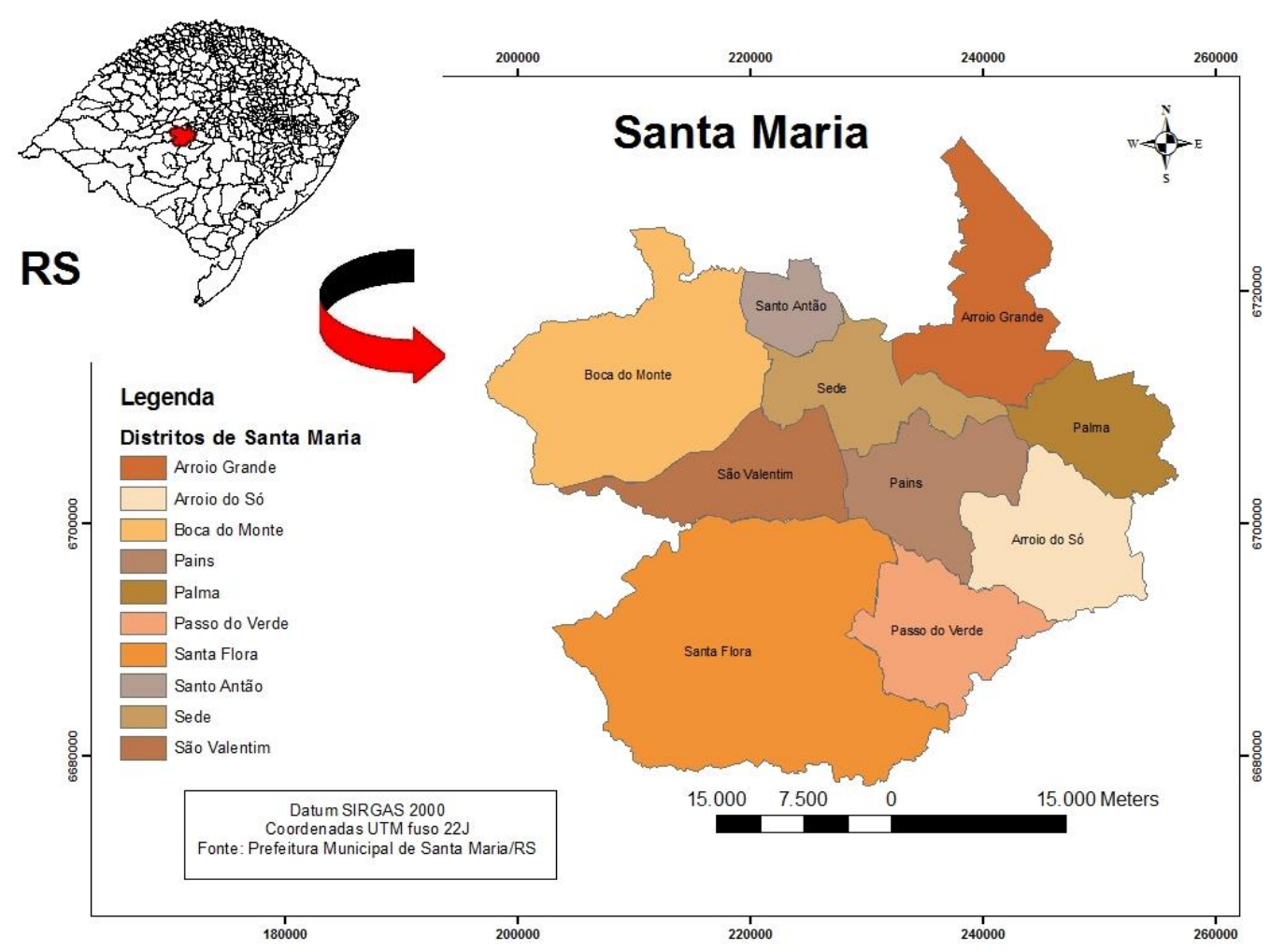

Fonte: Organizado pelos autores, 2016. 
Arroio Grande conta com uma população de 2701 habitantes, das quais 87,86\% pode ser considerada como rural de acordo com o IBGE (2010). É conhecido como o portal para a Quarta Colônia, o início da "Rota Gastronômica" ligando Santa Maria-RS a Silveira MartinsRS.

A ocupação do Arroio Grande teve início a partir de meados do século XIX, com a chegada de imigrantes italianos, sendo intensificada a partir de 1890, com o aumento das atividades agrícolas e comerciais, ligadas a extração de madeira e cultivo agrícola.

A produção agrícola do distrito está baseada na agricultura familiar, entre os produtos cultivados, destaca-se a produção de arroz, feijão, hortaliças, milho, mandioca, soja, assim como a comercialização de produtos coloniais. Entre os principais atrativos turísticos estão, balneários; Capela São Marcos; Paróquia São Pedro Apóstolo; Santuário Nossa Senhora do Rosário; Cantinas; Fábricas de Facas; restaurantes; agroindústrias; monumentos; o Museu do Imigrante; entre outros.

\section{METODOLOGIA}

A presente pesquisa é de natureza exploratória descritiva que, segundo Gil (2010), oferece maior familiaridade com o problema, ao ser flexível e considerar diversos aspectos do objeto estudado. Utilizou-se de estudo de caso por ser uma análise mais profunda e exaustiva permitindo amplo e detalhado conhecimento, o qual deve ser realizado com a utilização de diferentes métodos e uma abordagem qualitativa para análise dos dados. No presente trabalho foram utilizados a observação direta, diário de campo, revisão bibliográfica e entrevistas semiestruturadas.

A análise da dinâmica espacial da multifuncionalidade do espaço rural do Distrito de Arroio Grande-Santa Maria/RS, é classificada como descritiva qualitativa, utilizando como suporte para a espacialização das informações o programa Statistical Package for the Social Sciences (SPSS) e o programa ArcGIS 9.2.

A presente pesquisa foi realizada concomitantemente ao Estudo da Realidade Rural do Distrito de Arroio Grande, desenvolvido pelo Grupo de Pesquisa em Extensão Rural Aplicada, coordenado pelo Prof. Dr. Clayton Hillig. Através do Estudo foram extraídos os dados referentes a análise do sistema de produção das unidades familiares diagnosticados através de entrevistas semiestruturadas e análise das novas ruralidades. 
Inicialmente realizamos levantamento bibliográfico para caracterizar a área de pesquisa com a leitura de artigos científicos e livros relacionados às questões de natureza teórica que abordem a temática. As análises foram focadas no conceito de sistemas de produção $^{3}$, multifuncionalidade e pluriatividade das unidades de produção. A construção da pesquisa está dividida em duas categorias de análise, referente as unidades de produção familiares e as ocupações rurais não agrícolas, conforme se apresenta:

- $\quad$ Categorias dos sistemas de produção (ocupações rurais agrícolas) relacionada somente às unidades de produção agrícola familiar ${ }^{4}$ (UPAFs).

- Categorias das ocupações rurais não agrícolas (multifuncionalidade do espaço rural).

Os dados qualitativos foram obtidos por meio de entrevistas semiestruturadas e observação direta. As entrevistas semiestruturadas foram dirigidas a 27 unidades de produção familiares (UPAFs) no espaço rural do Distrito e levantamento (cadastro) que inventaria os serviços/lugares/atividades/empreendimentos rurais não-agrícolas existentes no distrito de Arroio Grande identificados através das saídas a campo com o objetivo de melhor conhecêlos e caracterizá-los.

A partir do inventário sistematizou-se uma tipologia dos mesmos que indicam usos e funções múltiplas do rural. Os procedimentos de busca a campo foram direcionados principalmente a identificar e mapear propriedades rurais reconvertidas em empreendimentos de lazer, turismo rural, serviços agrícolas terceirizados, entrepostos de agrocomércio e fábricas.

Nesse sentido foram identificadas 29 unidades de ocupações não agrícolas obtidas pela observação direta em Arroio Grande e somando-se as UPAFs totaliza-se um universo de 54 amostras representativas da multifuncionalidade no distrito de Arroio Grande, município de Santa Maria-RS em 2012.

A amostra junto as UPAFs se caracteriza basicamente de agricultores familiares, compreendidos como aqueles sujeitos onde a "unidade de produção/propriedade e trabalho estão intimamente ligados à família”, conforme Lamarche, (1993, p.15).

As entrevistas ocorreram de forma direta, com questões abertas e fechadas, com o propósito de conhecer os sistemas de produção presentes na agricultura familiar de Arroio Grande, a inserção das atividades agrícolas e não agrícolas nesse espaço rural assim como a presença da pluriatividade. 
A amostragem das UPAFs é caracterizada como probabilística (aleatória) e definida por conglomerados, ou seja, as localidades rurais do Distrito de Arroio Grande, onde a população é dividida, extraindo-se uma amostra apenas dos conglomerados selecionados: Sede do distrito, Cidade dos Meninos, Nossa Senhora da Saúde, Canudos, São Marcos, Três Barras, Arroio do Veado, Invernadinha e Arroio Lobato, conforme Figura 2.

Figura 2: Localização da área de estudo e áreas pesquisadas no Distrito de Arroio Grande

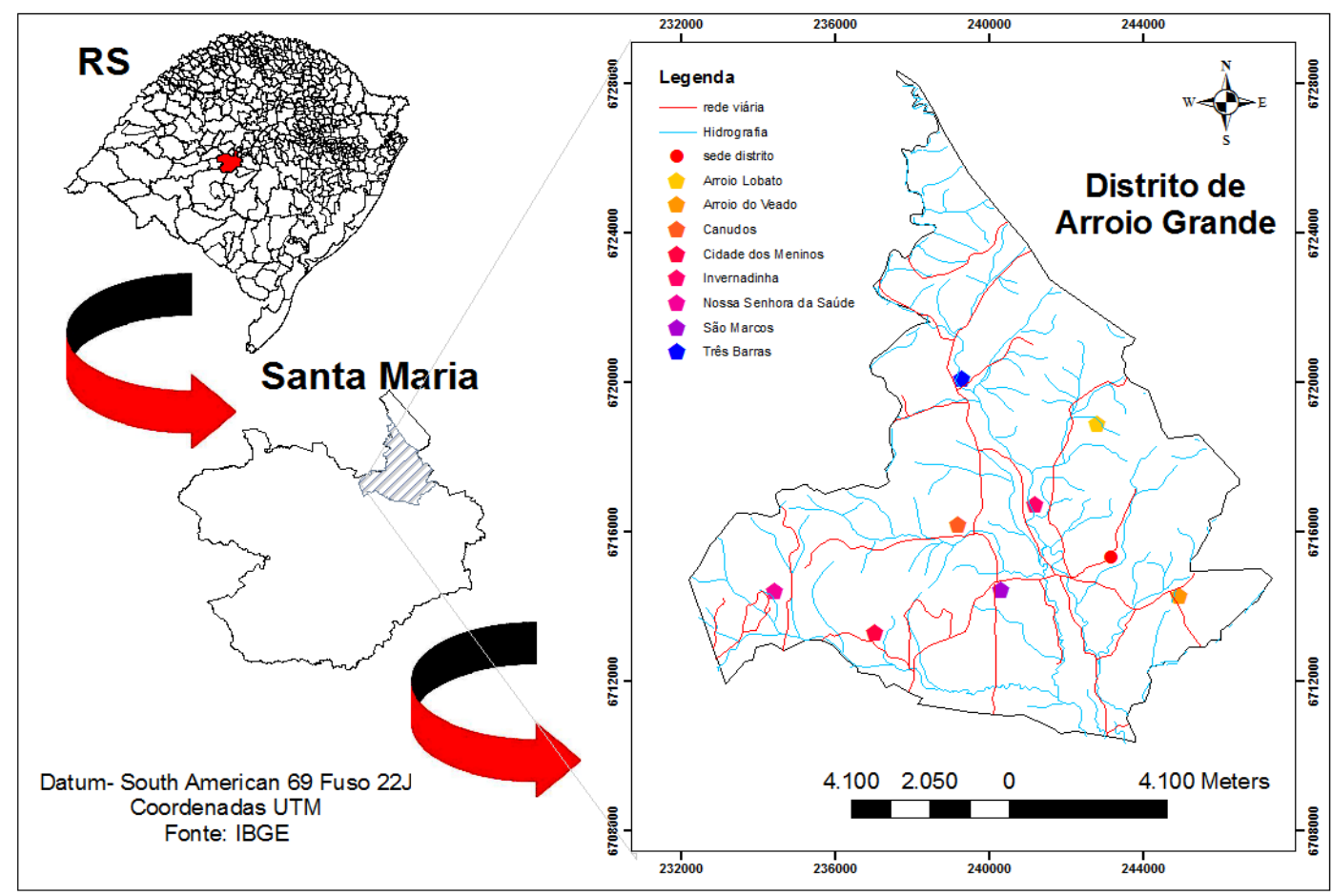

Fonte: Elaborado pelos autores (2015).

Nesse sentido, as análises das ocupações rurais agrícolas partem do diagnóstico do sistema de produção, oriundas neste caso do estudo da realidade do Distrito de Arroio Grande. Através da análise das entrevistas e dos dados de observação direta, registrada no diário de campo, com os agricultores familiares, foram diagnosticadas variáveis para tratamento dos dados que identificam a dinâmica do sistema de produção, nos aspectos sociais, ambientais e econômicos, sendo estas: sexo, idade, escolaridade, localidade em que mora, atividades agrícolas, atividades não agrícolas e área total da propriedade, todos esses dados se referem ao chefe da família.

A análise das ocupações rurais não agrícolas foi diagnosticada por observação direta, em todas as áreas pesquisadas, pela revisão bibliográfica e classificadas nas tipologias de 
lazer e turismo, empreendimentos, beneficiamento, serviços e patrimônio histórico cultural, seguindo as tipologias já determinadas pelo estudo desenvolvido por Froehlich et al. (2008) da multifuncionalidade do espaço rural na região central do Rio Grande do Sul. O referente estudo já apontava o crescimento do setor de serviços no meio rural como a descrição de novas funções onde se apresenta uma segmentação de produtos turísticos e de lazer.

$\mathrm{Na}$ sistematização de dados para mapeamento da dinâmica espacial da multifuncionalidade do espaço agrário do Distrito de Arroio Grande utilizou-se das tipologias rurais não agrícolas e agrícolas para determinação dos mapas temáticos, oriundos da mosaicagem e georreferenciamento das cartas topográficas, e imagens orbitais para extração de dados e digitalização de temas como: rede viária, rede de drenagem, localidades e curvas de nível, entre outros.

As categorias de análise dos sistemas de produção são derivadas da presença de atividades não agrícolas e agrícolas, que compõem a renda das famílias rurais entrevistadas. O critério fundamental na definição do sistema de produção foi à atividade produtiva predominante, que imprime a dinâmica da unidade de produção da agricultura familiar.

Na montagem do mosaico digital do distrito foram tomados pontos de apoio das cartas (DSG) e de imagens de satélite, onde se procedeu à digitalização do polígono máscara (limite distrital - determinado pela lei de criação do município), fazendo uso de aplicativos computacionais e sofwares específicos para geoprocessamento ArcGIS. Foram coletadas as coordenadas UTM no Datum South American 69, das ocupações agrícolas e não agrícolas em análise.

\section{RESULTADOS E DISCUSSÃO}

\section{Atividades agrícolas e não agrícolas presentes no Distrito de Arroio Grande}

O novo rural está ressurgindo num movimento de reorientação da capacidade produtiva da população rural com a absorção de novos componentes econômicos, culturais e sociais. Ao adotarmos a perspectiva de um novo rural estamos aceitando que as complexas relações da natureza com a sociedade estão moldando as formas de produção fazendo surgir atividades agrícolas e não agrícolas ancoradas numa visão sócio-política, a qual, defende que a atividade agrícola não se esgota na produção de alimentos e oferece a sociedade uma gama de bens tangíveis e intangíveis ligados ao simbólico e principalmente ao contato com a natureza (WANDERLEY, 2003, CARNEIRO e MALUF, 2003, FROEHLICH, 2002). 
Os dados coletados pelas entrevistas possibilitaram a compreensão das atividades agrícolas e não agrícolas detectadas pela análise do sistema de produção. Em muitas propriedades há necessidade de outras rendas (atividades não agrícolas ou aposentadorias) para viabilizar a atividade agrícola no estabelecimento agrícola familiar e a permanência da família no meio rural.

O estudo teve enfoque no sistema de produção familiar pois conforme Dufumier (1996), o estabelecimento agrícola é a célula base do processo de produção agrícola, o lugar onde se relacionam os elementos biotécnicos e socioeconômicos, compreendem os insumos, os produto, subprodutos e serviços, estocados, transformados ou vendidos, e os meios de produção (equipamentos, glebas, animais, capital, maquinário) sob direção do agricultor e sua família.

Diversos autores se utilizam do diagnóstico do sistema agrário para definir os fenômenos sociais, econômicos, ambientais e/ou culturais que se inter-relacionam com as questões agrárias. Segundo Neumann e Fialho, (2009, p.45) o enfoque do diagnóstico de um sistema agrário se "concentra em uma abordagem sistêmica, que divide a realidade em partes independentes, as quais se constituem em unidades de investigação separadas".

A presente análise identifica a presença da multifuncionalidade e consequente pluriatividade do espaço agrário, permitindo a espacialização das tipologias agrícolas e não agrícolas. A análise do sistema de produção foi fundamentada nas entrevistas com agricultores familiares dispersos nas localidades do Distrito de Arroio Grande, tendo como total 27 entrevistas, conforme Quadro 1.

Quadro 1: Propriedades agrícolas familiares entrevistadas

\begin{tabular}{|c|c|c|}
\hline $\begin{array}{c}\text { UNIDADE DE PRODUÇÃO } \\
\text { AGRÍCOLA FAMILIAR - } \\
\text { UPAF }\end{array}$ & SISTEMAS DE PRODUÇÃO & LOCALIDADE \\
\hline UPAF 1 & Fumo & Três Barras \\
\hline UPAF 2 & Fumo & Três Barras \\
\hline UPAF 3 & Grãos & São Marcos \\
\hline UPAF 4 & Grãos, hortifruticultura e pecuária & São Marcos \\
\hline UPAF 5 & hortifruticultura & São Marcos \\
\hline UPAF 6 & Grãos, hortifruticultura e pecuária & Nossa Sra da Saúde \\
\hline UPAF 7 & Grãos & Arroio de Veado \\
\hline UPAF 8 & Grãos, hortifruticultura e pecuária & Arroio de Veado \\
\hline
\end{tabular}


Revista de Geografia (Recife) V. 34, No. 2, 2017

\begin{tabular}{|c|c|c|}
\hline UPAF 9 & Grãos, pecuária e fumo & Três Barras \\
\hline UPAF 10 & Grãos, hortifruticultura e pecuária & Três Barras \\
\hline UPAF 11 & Grãos e pecuária & Canudos \\
\hline UPAF 12 & Grãos, hortifruticultura e pecuária & Arroio de Veado \\
\hline UPAF 13 & Grãos, hortifruticultura e pecuária & São Marcos \\
\hline UPAF 14 & Grãos, hortifruticultura e pecuária & Cidade dos Meninos \\
\hline UPAF 15 & Grãos, hortifruticultura e pecuária & Cidade dos Meninos \\
\hline UPAF 16 & Auto-consumo & Arroio Lobato \\
\hline UPAF 17 & Grãos, hortifruticultura e pecuária & Arroio Lobato \\
\hline UPAF 18 & Auto-consumo & Invernadinha \\
\hline UPAF 19 & Hortifruticultura e pecuária & São Marcos \\
\hline UPAF 20 & Grãos, hortifruticultura e pecuária & São Marcos \\
\hline UPAF 21 & Grãos, hortifruticultura e pecuária & São Marcos \\
\hline UPAF 22 & hortifruticultura & São Marcos \\
\hline UPAF 23 & Grãos, hortifruticultura e pecuária & Invernadinha \\
\hline UPAF 24 & Grãos, hortifruticultura e pecuária & Canudos \\
\hline UPAF 25 & Grãos, hortifruticultura e pecuária & Invernadinha \\
\hline UPAF 26 & hortifruticultura & Invernadinha \\
\hline UPAF 27 & Hortifruticultura e pecuária & Canudos \\
\hline
\end{tabular}

Fonte: Dados de campo, 2013.

É possível constatar que $51,85 \%$ das unidades de produção se dedicam ao sistema de produção integrando o cultivo de grãos, hortifruticultura e pecuária. A inserção de cultivos diversificados e da pecuária, tem possibilitado novas dinâmicas sociais e econômicas ao Distrito de Arroio do Grande. Procurando viabilizar as unidades os agricultores investem em várias atividades e, posteriormente, mantêm o foco nas que oferecem maior retorno.

No que diz respeito ao gênero dos proprietários, o estudo evidencia o predomínio absoluto de UPAFs comandadas por homens como demonstra a tabela 1. Sendo encontrada somente duas unidades de produção em que as mulheres estão a frente dos trabalhos na propriedade.

Tabela 1: Frequência de gênero dos entrevistados observada nas localidades

\begin{tabular}{lccccccccc}
\hline Gênero & $\begin{array}{c}\text { Cidade } \\
\text { dos } \\
\text { Meninos }\end{array}$ & $\begin{array}{c}\text { São } \\
\text { Marcos }\end{array}$ & Canudos & $\begin{array}{c}\text { Arroio } \\
\text { do } \\
\text { Veado }\end{array}$ & Invernadinha & $\begin{array}{c}\text { Três } \\
\text { Barras }\end{array}$ & $\begin{array}{c}\text { Nossa } \\
\text { Senhora } \\
\text { da Saúde }\end{array}$ & $\begin{array}{c}\text { Arroio } \\
\text { Lobato }\end{array}$ & Total \\
\hline Masculino & 2 & 6 & 3 & 3 & 4 & 4 & 1 & 2 & 25 \\
Feminino & 0 & 2 & 0 & 0 & 0 & 0 & 0 & 0 & 2
\end{tabular}


Total

$2 \quad 8$

Fonte: Dados de campo, 2013.

A tabela 2, que segue informa acerca das faixas etárias predominantes entre os proprietários da UPAFs, predominando faixa etária entre 51-70, estes representam quase 60\% do total dos entrevistados, ratificando dados constantes na literatura nacional acerca do envelhecimento da população residente nas áreas rurais.

Tabela 2: Frequência da idade dos entrevistados observada nas localidades

\begin{tabular}{|c|c|c|c|c|c|c|c|c|c|}
\hline $\begin{array}{l}\text { Idade } \\
\text { (anos) }\end{array}$ & $\begin{array}{c}\text { Cidade dos } \\
\text { Meninos }\end{array}$ & $\begin{array}{c}\text { São } \\
\text { Marcos }\end{array}$ & Canudos & $\begin{array}{c}\text { Arroio do } \\
\text { Veado }\end{array}$ & Invernadinha & $\begin{array}{c}\text { Três } \\
\text { Barras }\end{array}$ & $\begin{array}{c}\text { Nossa } \\
\text { Senhora da } \\
\text { Saúde }\end{array}$ & $\begin{array}{l}\text { Arroio } \\
\text { Lobato }\end{array}$ & Total \\
\hline Até 40 & 0 & 1 & 0 & 0 & 0 & 3 & 0 & 0 & 4 \\
\hline $41-50$ & 1 & 2 & 0 & 1 & 1 & 0 & 0 & 0 & 5 \\
\hline $51-60$ & 0 & 2 & 1 & 2 & 2 & 0 & 1 & 0 & 8 \\
\hline $\begin{array}{l}61-70 \\
\text { mais de }\end{array}$ & 1 & 2 & 2 & 0 & 1 & 0 & 0 & 2 & 8 \\
\hline 70 & 0 & 1 & 0 & 0 & 0 & 1 & 0 & 0 & 2 \\
\hline Total & 2 & 8 & 3 & 3 & 4 & 4 & 1 & 2 & 27 \\
\hline
\end{tabular}

Fonte: Dados de campo, 2013.

Quanto à dimensão das propriedades entrevistadas, observa-se que no distrito de Arroio Grande, ocorre o predomínio das pequenas propriedades ${ }^{5}$ rurais, fato confirmado com a pesquisa de campo, onde se verificou que 66,6\% dos agricultores familiares entrevistados atingem até 20 ha e $29 \%$ possuem áreas que vão de 21 a 90 hectares. O expressivo número de pequenas propriedades demonstram a presença da minifundização ${ }^{6}$ dos estabelecimentos rurais, fato esse motivado prioritariamente pela subdivisão das unidades agrícolas. Esse processo é motivado, principalmente, pela subdivisão das propriedades agrícolas pela herança.

$\mathrm{Na}$ sequência, se descreve as tabelas de contingências, referenciando o tamanho da propriedade com a escolaridade do proprietário (Tabela 3).

Tabela 3: Tabela de contingência de escolaridade e área da propriedade dos entrevistados no distrito

\begin{tabular}{|c|c|c|c|c|c|c|c|c|c|c|c|c|}
\hline \multirow{2}{*}{ Escolaridade } & \multicolumn{11}{|c|}{ Área (ha) } & \multirow{2}{*}{ Total } \\
\hline & Até 10 & $11-20$ & $21-30$ & $31-40$ & $41-50$ & 51-60 & 61-70 & 71-80 & $81-90$ & $91-100$ & $>101$ & \\
\hline Fundamental incompleto & 8 & 6 & 2 & 0 & 0 & 0 & 0 & 1 & 1 & 0 & 0 & 18 \\
\hline Fundamental completo & 0 & 0 & 0 & 1 & 0 & 0 & 0 & 0 & 0 & 0 & 1 & 2 \\
\hline Netto et al., 2017 & & & & & $\mathrm{V010}$ & $4-549$ & & & & & & \\
\hline
\end{tabular}




\begin{tabular}{lllllllllllll} 
Médio incompleto & 1 & 1 & 0 & 0 & 0 & 0 & 0 & 0 & 0 & 0 & 0 & 2 \\
Médio completo & 0 & 1 & 0 & 1 & 0 & 0 & 0 & 1 & 0 & 0 & 0 & 3 \\
Ensino técnico & 0 & 0 & 1 & 0 & 0 & 0 & 0 & 0 & 0 & 0 & 0 & 1 \\
Pós-graduação & 0 & 1 & 0 & 0 & 0 & 0 & 0 & 0 & 0 & 0 & 0 & 1 \\
\hline Total & 9 & 9 & 3 & 2 & 0 & 0 & 0 & 2 & 1 & 0 & 1 & 27 \\
\hline
\end{tabular}

Fonte: Dados de campo, 2013.

A análise das entrevistas permite afirmar que os entrevistados possuem diversidade nos sistemas produtivos, podendo vir a interagir atividades agrícolas e não agrícolas. Se definem como agricultores pluriativos devido a essa diversidade e até por virem a apresentar fontes de rendas agrícolas e não agrícolas. As atividades não agrícolas dos entrevistados foram descritas a partir da ordem de respostas obtidas nas entrevistas, sendo estas: arrendamento, aposentadoria, serviços urbanos e agroindústria (Tabela 4).

Tabela 4: Frequência das atividades não agrícolas do sistema de produção dos entrevistados nas localidades

\begin{tabular}{|c|c|c|c|c|c|c|c|c|c|}
\hline \multirow[b]{2}{*}{ Atividades não agrícolas } & \multicolumn{8}{|c|}{ Localidade } & \multirow[b]{2}{*}{ Total } \\
\hline & $\begin{array}{c}\text { Cidade } \\
\text { dos Meninos }\end{array}$ & São Marcos & Canudos & $\begin{array}{c}\text { Arroio } \\
\text { do Veado }\end{array}$ & Invernadinha & $\begin{array}{c}\text { Três } \\
\text { Barras }\end{array}$ & $\begin{array}{c}\text { Nossa } \\
\text { Senhora } \\
\text { Da Saúde }\end{array}$ & $\begin{array}{l}\text { Arroio } \\
\text { Lobato }\end{array}$ & \\
\hline Não possui & 0 & 2 & 0 & 3 & 0 & 0 & 0 & 1 & 6 \\
\hline Arrendamento & 1 & 0 & 0 & 0 & 0 & 2 & 0 & 0 & 3 \\
\hline Aposentadoria & 0 & 5 & 0 & 0 & 0 & 2 & 1 & 0 & 8 \\
\hline $\begin{array}{l}\text { Arrendamento e } \\
\text { Aposentadoria }\end{array}$ & 0 & 0 & 0 & 0 & 2 & 0 & 0 & 0 & 2 \\
\hline Serviços urbanos & 1 & 0 & 0 & 0 & 1 & 0 & 0 & 0 & 2 \\
\hline $\begin{array}{l}\text { Aposentadoria e } \\
\text { serviços urbanos }\end{array}$ & 0 & 1 & 0 & 0 & 0 & 0 & 0 & 0 & 1 \\
\hline Aposentadoria e agroindústria & 0 & 0 & 0 & 0 & 0 & 0 & 0 & 1 & 1 \\
\hline $\begin{array}{c}\text { Arrendamento, aposentadoria e } \\
\text { Serviços urbanos }\end{array}$ & 0 & 0 & 2 & 0 & 1 & 0 & 0 & 0 & 3 \\
\hline Agroindustria & 0 & 0 & 1 & 0 & 0 & 0 & 0 & 0 & 1 \\
\hline Total & 2 & 8 & 3 & 3 & 4 & 4 & 1 & 2 & 27 \\
\hline
\end{tabular}

Fonte: Dados de campo, 2013.

Observa- se a presença de aposentadoria em 44,4\% dos entrevistados, o que vai ao encontro com o que destaca Graziano da Silva (2001). [...] as famílias rurais brasileiras estão cada vez mais se tornando não agrícolas e garantindo sua sobrevivência mediante transferências sociais (aposentadorias e pensões).

Mais de setenta por cento $(77,8)$ dos entrevistados possuem atividades não agrícolas as quais indicam a multifuncionalidade do espaço rural e principalmente da pluriatividade do 
meio rural o qual diversifica cada vez mais a produção não apenas agregando valor somente da atividade agrícola, recorrendo a atividades não agrícolas as quais compreendem novas dinâmicas sociais, portanto a presença de uma nova ruralidade deste espaço agrário, cuja espacialidade podemos observar na Figura 3 que segue.

Figura 3: Mapa do sistema de produção da agricultura familiar do Distrito de Arroio Grande, Santa Maria-RS

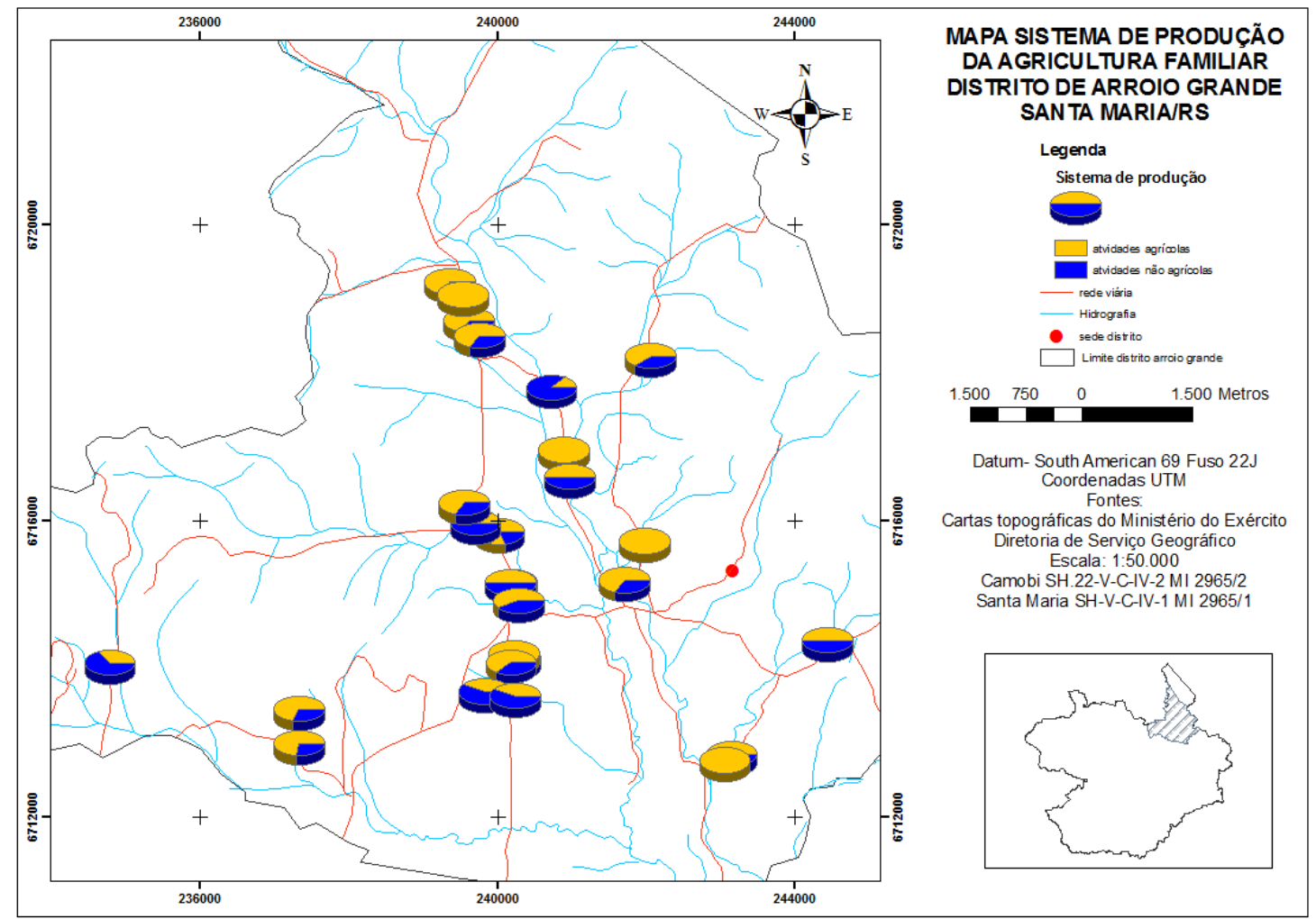

Fonte: Organizado pelos autores (2015).

Destaca-se a agroindústria nos produtos coloniais, onde os agricultores familiares de Arroio Grande são presença constante em feiras do município de Santa Maria, onde possuem ponto fixo num acesso de venda o que gera para eles uma identidade na confecção dos produtos coloniais, como queijos, bolachas, pães, doces em compotas, rapaduras e massas caseiras, informações essas obtidas pelas entrevistas.

No que diz respeito a relação entre área útil da propriedade e atividades não agrícolas a pesquisa constatou que quanto menor for o tamanho maior a necessidade de complementar a renda agrícola com rendas não agrícolas, o que para a literatura especializada é uma estratégia que viabiliza a reprodução socioeconômica da família camponesa. A Tabela 5 sistematiza esses dados. 
Tabela 5: Frequência das atividades não agrícolas do sistema de produção e área útil da propriedade

\begin{tabular}{|c|c|c|c|c|c|c|c|c|c|c|}
\hline \multirow[b]{2}{*}{$\begin{array}{c}\text { Área útil } \\
\text { ha }\end{array}$} & \multicolumn{9}{|c|}{ Atividades não agrícolas } & \multirow[b]{2}{*}{ Total } \\
\hline & $\begin{array}{c}\text { Não } \\
\text { possui }\end{array}$ & $\begin{array}{c}\text { Arrenda- } \\
\text { mento }\end{array}$ & $\begin{array}{c}\text { Aposenta- } \\
\text { doria }\end{array}$ & $\begin{array}{l}\text { Arrenda- } \\
\text { mento e } \\
\text { aposen- } \\
\text { tadoria }\end{array}$ & $\begin{array}{l}\text { Serviço } \\
\text { urbano }\end{array}$ & $\begin{array}{c}\text { Aposenta- } \\
\text { doria e } \\
\text { serviços } \\
\text { urbanos }\end{array}$ & $\begin{array}{l}\text { Aposenta- } \\
\text { doria e } \\
\text { agroin- } \\
\text { dústria }\end{array}$ & $\begin{array}{c}\text { Arrenda- } \\
\text { mento, } \\
\text { Aposenta- } \\
\text { doria e } \\
\text { Serviços } \\
\text { urbanos }\end{array}$ & $\begin{array}{l}\text { Agroin- } \\
\text { dústria }\end{array}$ & \\
\hline Até 10 & 1 & 2 & 3 & 1 & 0 & 1 & 0 & 1 & 0 & 9 \\
\hline $11-20$ & 2 & 0 & 3 & 0 & 1 & 0 & 1 & 2 & 0 & 9 \\
\hline $21-30$ & 0 & 0 & 2 & 1 & 0 & 0 & 0 & 0 & 0 & 3 \\
\hline $31-40$ & 0 & 1 & 0 & 0 & 0 & 0 & 0 & 0 & 1 & 2 \\
\hline $41-50$ & 0 & 0 & 0 & 0 & 0 & 0 & 0 & 0 & 0 & 0 \\
\hline $51-60$ & 0 & 0 & 0 & 0 & 0 & 0 & 0 & 0 & 0 & 0 \\
\hline $61-70$ & 0 & 0 & 0 & 0 & 0 & 0 & 0 & 0 & 0 & 0 \\
\hline $71-80$ & 1 & 0 & 0 & 0 & 1 & 0 & 0 & 0 & 0 & 2 \\
\hline $81-90$ & 1 & 0 & 0 & 0 & 0 & 0 & 0 & 0 & 0 & 1 \\
\hline 91-100 & 0 & 0 & 0 & 0 & 0 & 0 & 0 & 0 & 0 & 0 \\
\hline$>101$ & 1 & 0 & 0 & 0 & 0 & 0 & 0 & 0 & 0 & 1 \\
\hline Total & 6 & 3 & 8 & 2 & 2 & 1 & 1 & 3 & 1 & 27 \\
\hline
\end{tabular}

Fonte: Dados de campo, 2013.

Dentre os sistemas de produção verificados junto às entrevistas, nas propriedades de agricultura familiar, destacam-se as atividades agrícolas de produção de grãos e hortifruticultura. Conforme o estudo de realidade rural do distrito a renda principal da propriedade é representada pela produção de grãos, a orizicultura com $27 \%$ e a hortifruticultura também com $27 \%$, seguidos pela renda do fumo com $10 \%$ e após pecuária e soja empatadas a 3\% (Figura 4).

Figura 4: Principal renda das propriedades agrícolas familiares do distrito de Arroio Grande

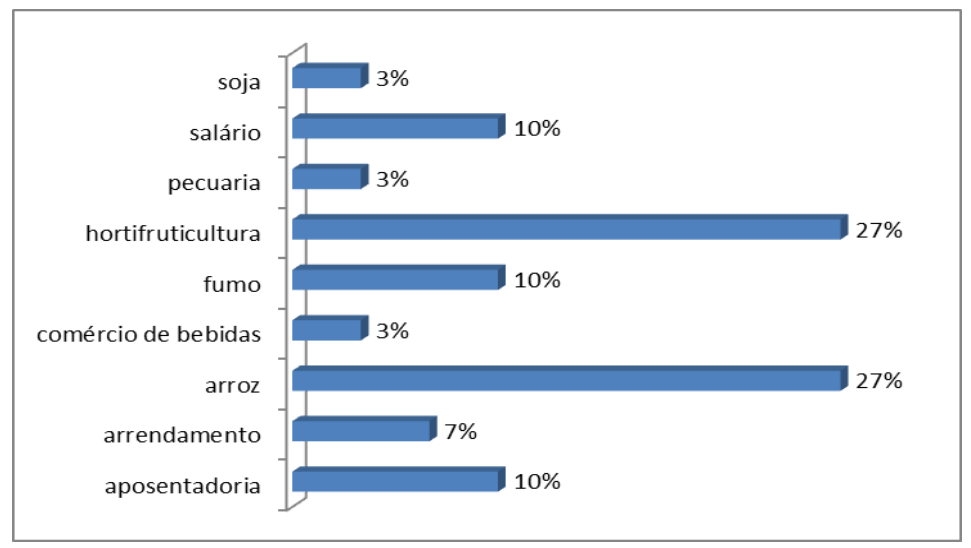

Fonte: Estudo da realidade rural do distrito de Arroio Grande, 2012. 
As atividades agrícolas podem ser observadas pela área útil da propriedade, tendo como exemplo a atividade de subsistência e fumo que estão relacionadas a áreas menores, e a atividade de cultura de grãos frequentemente associada a áreas maiores por serem caracterizados por monocultivos e altamente mecanizados (Tabela 6).

Ainda no que diz respeito a variável área útil da propriedade é possível afirmarmos que as menores propriedades especializam-se na produção para o auto-consumo ou atividade fumageira, ao passo que a produção de grãos ocorre nas propriedades com maior área útil.

Tabela 6: Frequência das atividades agrícolas do sistema de produção relacionadas à área útil da propriedade

\begin{tabular}{|c|c|c|c|c|c|c|c|c|c|}
\hline \multirow[b]{2}{*}{$\begin{array}{l}\text { Área } \\
\text { útil } \\
\text { (ha) }\end{array}$} & \multicolumn{8}{|c|}{ Atividades agrícolas } & \multirow[b]{2}{*}{ Total } \\
\hline & $\begin{array}{l}\text { Auto- } \\
\text { consumo }\end{array}$ & Grãos & $\begin{array}{c}\text { Hortifru- } \\
\text { ticultura }\end{array}$ & Fumo & $\begin{array}{c}\text { Grãos e } \\
\text { Pecuária }\end{array}$ & $\begin{array}{c}\text { Hortifruti- } \\
\text { cultura e } \\
\text { Pecuária }\end{array}$ & $\begin{array}{c}\text { Grãos, } \\
\text { Pecuária e } \\
\text { Fumo }\end{array}$ & $\begin{array}{c}\text { Grãos, } \\
\text { Hortifruticul- } \\
\text { tura e Pecuária }\end{array}$ & \\
\hline Até 10 & 0 & 0 & 2 & 2 & 0 & 2 & 0 & 3 & 9 \\
\hline $11-20$ & 2 & 0 & 0 & 0 & 0 & 0 & 1 & 6 & 9 \\
\hline 21-30 & 0 & 1 & 1 & 0 & 0 & 0 & 0 & 1 & 3 \\
\hline $31-40$ & 0 & 0 & 0 & 0 & 1 & 0 & 0 & 1 & 2 \\
\hline $41-50$ & 0 & 0 & 0 & 0 & 0 & 0 & 0 & 0 & 0 \\
\hline $51-60$ & 0 & 0 & 0 & 0 & 0 & 0 & 0 & 0 & 0 \\
\hline $61-70$ & 0 & 0 & 0 & 0 & 0 & 0 & 0 & 0 & 0 \\
\hline 71-80 & 0 & 0 & 0 & 0 & 0 & 0 & 0 & 2 & 2 \\
\hline $81-90$ & 0 & 0 & 0 & 0 & 0 & 0 & 0 & 1 & 1 \\
\hline $90-100$ & 0 & 0 & 0 & 0 & 0 & 0 & 0 & 0 & 0 \\
\hline$>101$ & 0 & 1 & 0 & 0 & 0 & 0 & 0 & 0 & 1 \\
\hline Total & 2 & 2 & 3 & 2 & 1 & 2 & 1 & 14 & 27 \\
\hline
\end{tabular}

Fonte: Dados de campo, 2013.

Em relação ao índice sócio econômico observou-se que nas localidades de Arroio do veado, Invernadinha, Arroio Lobato se tem os maiores índices de área útil, o que corresponde à cultura de grãos nessas localidades soja e arroz. Já na localidade de Três barras áreas menores de cultivo que também vai de encontro à cultura de fumo.

Os dados coletados referentes ao sistema de produção confirmam a presença da pluriatividade no espaço agrário, prova disso é a dedicação das famílias a um conjunto variado de atividades econômicas e produtivas, não necessariamente ligadas à agricultura ou ao cultivo da terra, e cada vez menos executadas dentro da unidade de produção.

O fenômeno da pluriatividade muitas vezes é associado ao crescimento do número de pessoas e famílias ocupadas em atividades não agrícolas, Schneider e Matos (2006), indicam a importância da observação que a manutenção das múltiplas inserções ocupacionais depende Netto et al., 2017 ISSN 0104-5490 119 
de um conjunto de variáveis e fatores relacionados à dinâmica das famílias e dos indivíduos que as compõem. O que então foi observado, no presente estudo, que as atividades de serviços urbanos, são desenvolvidas principalmente por filhos de agricultores e não pelo chefe de família.

As propriedades entrevistadas caracterizam bem a agricultura familiar, onde segundo a FAO o modelo familiar tem como característica a relação íntima entre trabalho e gestão, a direção do processo produtivo conduzido pelos proprietários, a ênfase na diversificação produtiva e na durabilidade dos recursos e na qualidade de vida, a utilização do trabalho assalariado em caráter complementar e a tomada de decisões imediatas, ligadas ao alto grau de imprevisibilidade do processo produtivo (FAO/INCRA, 1994).

Quanto as ocupações rurais não agrícolas foram diagnosticadas através das saídas de campo, mapeados e tipificados, no espaço rural do distrito de Arroio Grande 29 estabelecimentos com ocupações não agrícolas, conforme Figura 5, bem caracterizadas, atividade estas que estão aqui tipificadas em: lazer e turismo $6,90 \%$, empreendimentos $17,2 \%$, beneficiamento $31,05 \%$, serviços $31,05 \%$ e patrimônio histórico cultural $13,8 \%$ por meio de observação direta e revisão bibliográfica.

Figura 5: Mapa das ocupações rurais não agrícolas do distrito de Arroio Grande-Santa Maria/RS

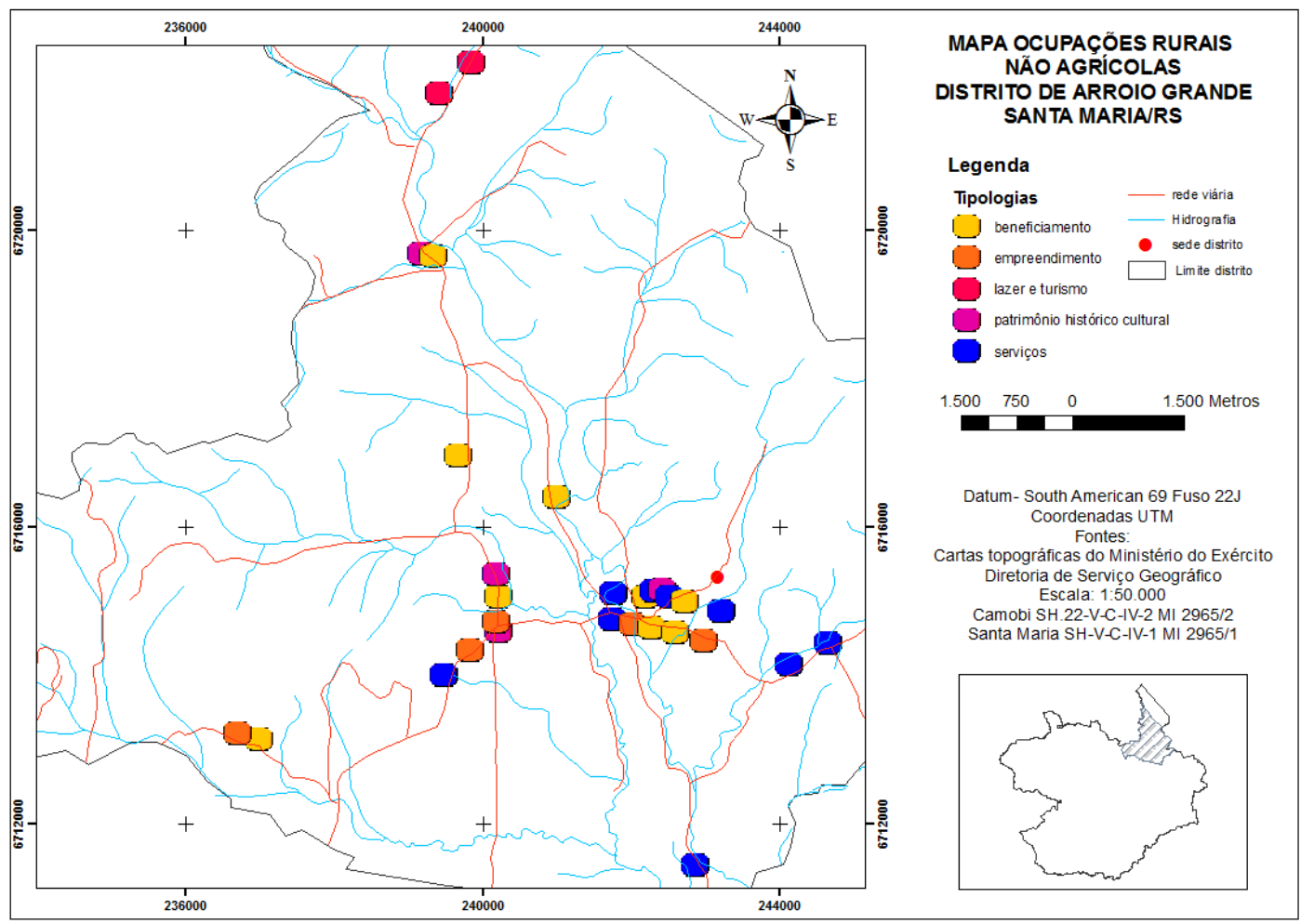

Fonte: Elaborado pelos autores (2015). 
$\mathrm{Na}$ tipologia de lazer e turismo foram mapeados 2 (dois) balneários, apesar de existirem cachoeiras visitadas no distrito as mesmas não foram referidas por não estarem formatadas, ou seja, não representam uma atividade de turismo e lazer concretizada, ainda que evidencie um potencial para a obtenção de rendas.

$\mathrm{Na}$ tipologia de empreendimentos foram mapeados 5 (cinco) atividades envolvendo restaurantes e comércio. Na tipologia de beneficiamento foram observados 9 (nove) atividades agroindústrias familiares, o que vem a demonstrar que a maioria destes empreendimentos se localizam nas proximidades de Santa Maria.

$\mathrm{Na}$ tipologia de serviços foram caracterizados a prestação de serviços terceirizados de pessoas ou grupos que moram no meio rural e os serviços públicos básicos ofertados no local como educação, saúde, segurança e administrativo, totalizando 9 (nove) observações.

$\mathrm{Na}$ tipologia de patrimônio cultural foram identificados 4 (quatro) locais com peculiaridades específicas de caráter histórico e cultural.

Através dos dados levantados, com os pontos georreferenciados das ocorrências tanto das atividades agrícolas como não agrícolas foi possível especializar as tipologias e a confecção de um banco de dados das informações das propriedades rurais entrevistadas e das ocupações rurais não agrícolas presentes no distrito. A espacialização das tipologias estudadas resultou no mapeamento da multifuncionalidade do espaço rural do distrito (Figura 6). 
Figura 6: Mapa da multifuncionalidade do distrito de Arroio Grande

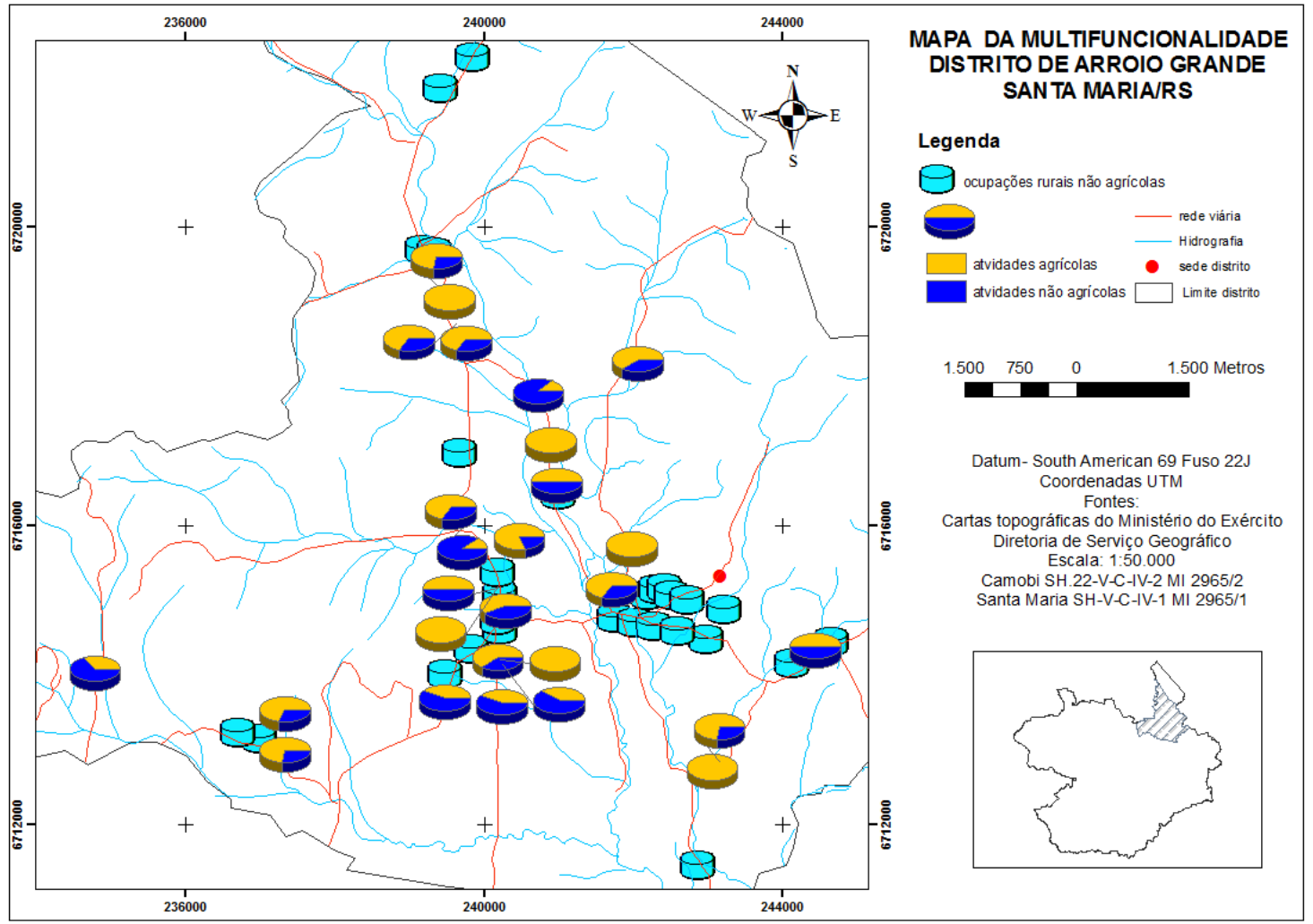

Fonte: Elaborado pelos autores (2015).

Nesta pesquisa o mapa é utilizado como um instrumento de subsídio às análises para as questões supracitadas. A espacialização das tipologias contribuiu para dois momentos importantes: o primeiro que consistiu na geração, atualização, integração e análise de informações georreferenciadas e/ou dados socioeconômicos da área de estudo e o segundo na representação cartográfica dos resultados obtidos.

Através dos dados levantados, com os pontos georreferenciados das ocorrências tanto das atividades agrícolas como não agrícolas foi possível especializar as tipologias e a confecção de um banco de dados das informações das propriedades rurais entrevistadas e das ocupações rurais não agrícolas presentes no distrito. A espacialização das tipologias estudadas possibilitou o mapeamento da multifuncionalidade do espaço rural do distrito.

O material cartográfico produzido nessa pesquisa é um subsidio para a compreensão dos fenômenos relativos as funções do novo rural que se manifestam no distrito de Arroio Grande, considerando as multifuncionalidades e a pluriatividade presentes. 


\section{CONSIDERAÇÕES FINAIS}

A partir da análise das tipologias estudadas, da produção de categorias de análise e tipologias das atividades agrícolas e não agrícolas, atingiu-se o objetivo de espacializar as informações georreferenciadas de dados que caracterizam a multifuncionalidade do espaço rural do Distrito de Arroio Grande-Santa Maria, RS. Certifica-se através da elaboração de mapas as novas funções que o distrito de Arroio Grande vêm desempenhando, um conjunto de atividades, vinculadas principalmente a crescente urbanização/proximidade do campo com as áreas urbanas, em referência a presença de atividades de lazer, turismo, indústrias e agroindústrias.

Através do diagnóstico das tipologias das ocupações rurais agrícolas e não agrícolas, foi possível à elaboração de mapas temáticos, identificando as diversas funções do rural e as atividades agrícolas e não agrícolas presentes no distrito. Foram sistematizados e especializados os sistemas de produção presentes na agricultura familiar e as ocupações rurais não agrícolas do distrito.

As famílias do rural buscam estratégias de sobrevivência com o desenvolvimento da pluriatividade e a realização de atividades e geração de renda não agrícolas, combinadas ou não com as atividades agrícolas. Conforme podemos observar a presença de atividades não agrícolas em $77,8 \%$ dos entrevistados onde $44,4 \%$ das unidades de produção entrevistadas contam com algum tipo de aposentadoria seja ela rural ou urbana.

O desenvolvimento rural sustentável deve subsidiar as políticas públicas considerando as multifuncionalidades e a pluriatividade presente no novo rural, um espaço agrário que deve ser focado pela perspectiva social, econômica e ambiental na dinâmica das relações sociais do território com a natureza, além de compreender a agricultura familiar como uma unidade social e não meramente produtiva. Apoiar a produção familiar e legitimar formas de produção que vinculem não somente rendas e sim a incorporação de novos valores simbólicos, tangíveis e intangíveis derivados da transformação cultural do novo espaço rural e das inter-relações sociais do mesmo com o ambiente, deve ser o foco dos gestores públicos.

\section{NOTAS}

${ }^{1}$ A multifuncionalidade surge como abordagem inovadora para se compreender a agricultura e os processos de desenvolvimento rural, a partir do reconhecimento e do fomento às diversas funções não diretamente produtivas associadas ao meio rural. Neste campo, construído a partir da crítica ao modelo agrícola produtivista, o enfoque recaí sobre o território, apreendendo-se as diferentes agriculturas e os diversos modos 
de vida que se reproduzem no rural a partir de um olhar territorializado, englobando os aspectos ecológicos, socioculturais e econômicos em cena (GAVIOLI, 2012, p. 18).

${ }^{2}$ Froehlich (2002) aponta uma diferenciação da região central do Estado do Rio Grande do sul, na maneira como a mercantilização se introduziu, não pelo viés econômico de industrialização, derivadas do pós fordismo e sim pela criação e agregação de novos valores de bens econômicos tangíveis e intangíveis oriundos de uma nova valoração social do rural, ocasionadas por uma mudança cultural advinda de preocupações ambientais e demandas ecológicas de contato com a natureza. "A preocupação ambiental tem jogado um papel determinante nas construções sociais do rural contemporâneo, produzindo novos sentidos para o rural, ao associá-lo de modo amplo a uma noção positivada de natureza" (FROEHLICH, 2002).

${ }^{3} \mathrm{O}$ sistema de produção é composto pelo conjunto de sistemas de cultivo e/ou de criação no âmbito de uma propriedade rural, definidos a partir dos fatores de produção (terra, capital e mão-de-obra) e interligados por um processo de gestão (HIRAKURI, 2012,p.13). No estudo realizado utilizamos de um estudo a partir da estrutura da Unidade referindo-se, principalmente, à caracterização dos meios de produção: como a mão-de-obra, a terra, os equipamentos e as instalações. Optamos para este estudo a caracterização a partir das unidades produtivas familiares pois segundo Neumann, (2003) o funcionamento do sistema corresponde ao estudo do encadeamento das decisões e ações que garantem a organização e a dinâmica do sistema de produção.

${ }^{4}$ Ao caracterizar o sistema de produção através da tipologia de agricultores familiares devemos considerar como característica fundamental, que o estabelecimento rural possua alguma atividade agropecuária que envolva familiares residentes no referido estabelecimento. Assim como atentar para a construção da família, onde a mesma só é considerada pelo grau de parentesco que une essas pessoas ou pela forma de adoção, devem compartilhar o mesmo espaço físico, do estabelecimento, e não de residência (NEUMANN e FIALHO, [2009]).

${ }^{5}$ Considera-se, neste estudo, pequena propriedade aquela que possui área entre um e quatro módulos fiscais (BRASIL, 1993).

${ }^{6}$ São considerados minifúndios as propriedades que possuem área inferior ao módulo fiscal. O módulo fiscal é uma medida expressa em hectares, fixada em cada município, que considera o tipo de exploração predominante do município e a renda obtida com a exploração predominante. Em função das atividades desenvolvidas em Santa Maria, um módulo fiscal corresponde a 22 hectares (INCRA, 2012).

\section{REFERÊNCIAS}

BRASIL. Lei n. 8629/93, de 25 de fevereiro de 1993. Dispõe sobre a regulamentação dos dispositivos relativos à reforma agrária. Diário Oficial [da] República Federativa do Brasil. Brasília, DF, 26 fev. $1993 . \quad$ Disponível em: <http://www.planalto.gov.br/ccivil_03/leis/18629.htm>. Acesso em: 20 abr. 2016. 
CARneIRO, M. J. (Org.); MALUF, Renato (Org.). Para Além da Produção: multifuncionalidade e agricultura familiar. 1. ed. Rio de Janeiro: Mauad, 2003. v. 1. 230 p. CONFERÊNCIA. Apresentação dos primeiros resultados e problematização do Estudo da Realidade Rural de Arroio Grande. Santa Maria.2010 Disponível em: $<$ http://w3.ufsm.br/reavacacai/index.php?option=com_content $\&$ task=view\&id=375\&Itemid= 188> Acesso em: 10 mar. 2012.

DUfUMIER, M. Les Projets de Développement Agricole . Manual d'Expertise . Paris: Ed. Khartala/CTA, 1996.

FAO/INCRA Diretrizes de Política Agrária e Desenvolvimento Sustentável. Brasília, Versão resumida do Relatório Final do Projeto UTF/BRA/036, março, 1994.

FROEHLICH, J. M. Rural e natureza: as construções sociais do rural contemporâneo. Rio de Janeiro: 2002, UFRRJ. Tese (Doutorado em Desenvolvimento Agricultura e Sociedade) área de concentração em Sociedade e Agricultura. Universidade Federal Rural do Rio de Janeiro. 2002

FROEHLICH, J. M.; DUlliUS, P. R.; PIETRZACKA, R. A multifuncionalidade do espaço rural na região central do RS - dados gerais. R. Bras. Agrociência. Pelotas, v.14, n.3-4, p.167-181, jul-set, 2008.

GAVIOLI, F. R. Multifuncionalidade da agricultura: concepções e aplicações aos estudos rurais. Sociedade e Desenvolvimento Rural. on line - v.6, n. 1 - Mar - 2012. p.12-31. Disponível em: www.inagrodf.com.br/revista

GIL, A. C., Como elabora projetos de pesquisa, São Paulo: Altas, 4 ed., 2010.

HIRAKURI, M.H.; DEBIASI, H.; PROCÓPIO, S. O.; FRANCLINI, J. C; CASTRO, C.

Sistemas de produção: conceitos e definições no contexto agrícola. - Londrina: Embrapa Soja, 2012. 24 p. (Documentos/ Embrapa Soja, n.335). Disponível em: http://www.cnpso.embrapa.br/download/Doc_335-OL.pdf. Acesso em: 10 de jul. 2016.

IBGE. Senso demográfico 2010. Disponível em: http://www.sidra.ibge.gov.br/ Acesso em: 10 de fev. 2016.

IBGE. Censo Demográfico. Disponível em:

<http://www.planalto.gov.br/ccivil_03/constituicao/constituicao.htm>. Acesso em: 15 ago. 2015.

INCRA. Estrutura Fundiária. 2012. Disponível em: <http://www.incra.gov.br/>. Acesso em: 14 mai. 2016. 
LACERDA, T. F. N.; MORUZZI MARQUES, P. E. Agricultura orgânica, apresentação territorial e reprodução social da agricultura familiar: os agricultores ecologistas da Encosta da Serra Geral em Santa Catarina. Revista Ruris, v. 2. Campinas: Ceres-IFCH, p.137-158, 2008 .

LAKATOS, E.; MARCONI, M.. Fundamentos de Metodologia Científica. São Paulo:Atlas, 1992.

LAMARCHE, H. (Coord.). A agricultura familiar I: uma realidade multiforme. Campinas: Ed. da Unicamp, 1993.

MOREIRA, M. A. Fundamentos do Sensoriamento Remoto e Metodologias de Aplicação. 3. ed. Viçosa: UFV, 2005.

NEUMANN, P. S. O impacto da fragmentação e do formato das terras nos sistemas familiares de produção. 2003, 320f. Tese (Doutorado em Engenharia de Produção) Universidade Federal de Santa Catarina, Florianópolis, 2003.

NEUMANN, P. S.; FIALHO,M.A.V.; Sistemas agrários. Apostila da disciplina análise de sistemas agrários. UFSM. [2009].71p.

PREFEITURA MUNICIPAL DE SANTA MARIA. Site oficial. Santa Maria, 2011. Disponível em: < http://www.santamaria.rs.gov.br/rural/index.php?secao=4>. Acesso em 20 jun. 2011.

PREFEITURA MUNICIPAL DE SANTA MARIA. Dados. Disponível em:

<http://www.santamaria.rs.gov.br/>. Acesso em: 10 juh. 2016.

SANTOS E. G. L. dos, COUTO V.de A. e ROCHA A. dos S. A multifuncionalidade e a questão agrária no Brasil: Uma análise da agricultura familiar como geradora das novas funções da agricultura. Exposição feita pelos autores em plenário, no $46^{\mathrm{a}}$ Congesso da SOBER Sociedade Brasileira de Economia Administração e Sociologia Rural, realizado em setembro de 2008.

SCHNEIDER, S. Agricultura familiar e industrialização: pluriatividade e descentralização industrial no Rio Grande do Sul. Porto Alegre, Editora da Universidade, 1999.

SCHNEIDER, S.; MATOS, E. J. de. A Pluriatividade no Meio Rural Gaúcho: caracterização e desafios para o desenvolvimento rural sustentável, Extensão Rural e Desenvolvimento Sustentável, v.2, n. 1/2, Porto Alegre, 2006.

SILVA, J. G. da. O novo rural Brasileiro. Belo Horizonte: Revista Nova Economia, 1997. Velhos e novos mitos do rural brasileiro. Estudos Avançados, São Paulo, v.15,n.43, p.37-50, 2001. 
WANDERLEY, M. N. B. A emergência de uma nova ruralidade nas sociedades modernas avançadas: o "rural" como espaço singular e ator coletivo. Estudos sociais e Agricultura, n. 5, p. 87-145, 2000.

WANDERley, M. N. B, Prefácio. In: CARnEIRO, M. J. (Org.) ; MALUF, Renato (Org.) . Para Além da Produção: multifuncionalidade e agricultura familiar. 1. ed. Rio de Janeiro: Mauad, 2003. v. 1. 230 p.

WANDERLEY, M. N. B. O 'Iugar' dos rurais: o meio rural no Brasil moderno. In: Anais. XXV Congresso da SOBER. Natal: SOBER. p.90-113. 1997. 